Pbar Note \#650

\title{
Design of Microwave Band Pass Filters for the Debuncher Stochastic Cooling System C. Deibele
}

\begin{abstract}
The FIR filters designed for the debuncher stochastic cooling system needed improvement. Its bandwidth was too wide, its magnitude was not flat, its phase ripple was too great, and it was difficult to control the characteristics of the filter. A simple microwave technique was employed to have a short time delay, simple robust layout, and small board size. A significant savings was seen over the FIR technique and these filters were installed in the Antiproton Source Debuncher while the FIR filters were removed from the debuncher stochastic cooling entirely.
\end{abstract}

\section{Introduction}

The debuncher stochastic cooling system requires narrowband filters to reduce the noise floor of the out-of-band signal. The original design that was employed in the Antiproton Source Debuncher was using a microwave FIR technique [1]. The FIR technique has a great advantage over many microwave techniques in that the FIR technique is inherently matched, whereas many microwave filtering techniques are not matched. This is to say, the out-of-band signals are typically reflected. It was thought that this reflection would be deleterious to our system, but upon further investigation the reflected signals from the filter could be reduced and tolerated with the use of fixed attenuators at the input and output of the filters. The filters were then added to the system and system performance improved accordingly. The filters were designed using a technique described by Pozar [2] and was optimized using Hewlett Packard's Touchstone Series IV Microwave Design Suite. The technique presented by Pozar is attractive because it can be easily optimized to fit specific design criteria, and the out-of-band transmission drops very quickly thereby having an excellent steep skirt. The results from Touchstone had to be further simulated and optimized electromagnetically with Ansoft's Ensemble 
because of the narrow bandwidth of the filter requirements and the frequency of interest is high enough such that some of the trace widths were approaching a size where the wavelength was critical.

\section{Design Considerations}

The method that Pozar

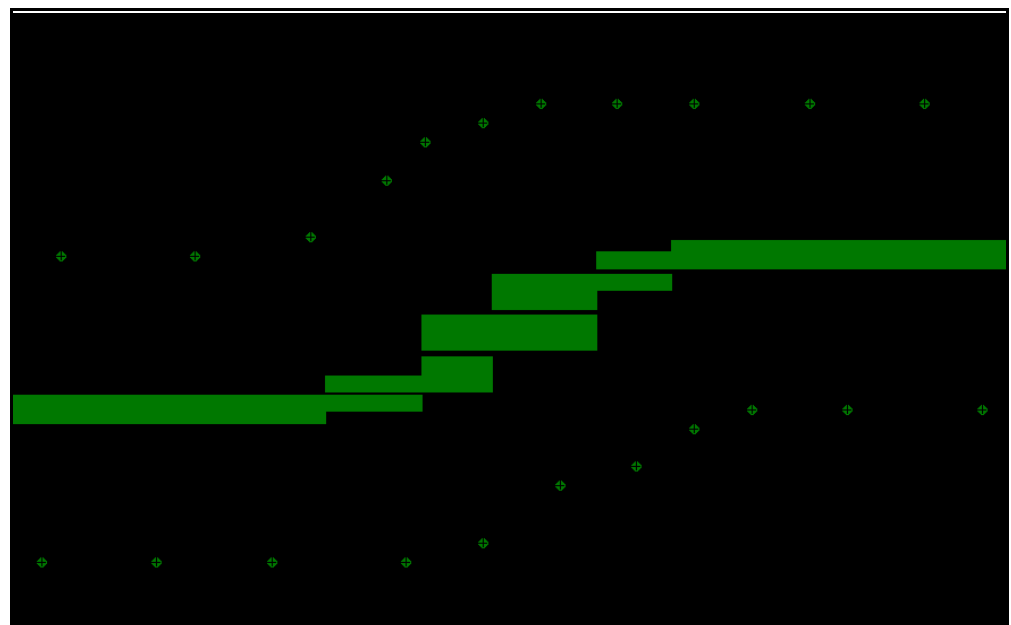

Figure 1. Actual size of the layout of one of the debuncher bandpass filters. The dots are via holes for bonding the top ground to the bottom ground. This filter uses four coupled lines.

presents in his text is very general

and the practicalities of a design can either make the system work ok or make it work poorly. A sample of the layout of a filter is shown in Fig. 1. A four coupled line model using a trial/error technique was chosen for the filter.

This choice was arrived at from simulation of three coupled lines, four coupled lines, and finally five coupled lines. Three coupled lines had too much magnitude and phase ripple, and five coupled lines took too much time to simulate electromagnetically and was very difficult to optimize

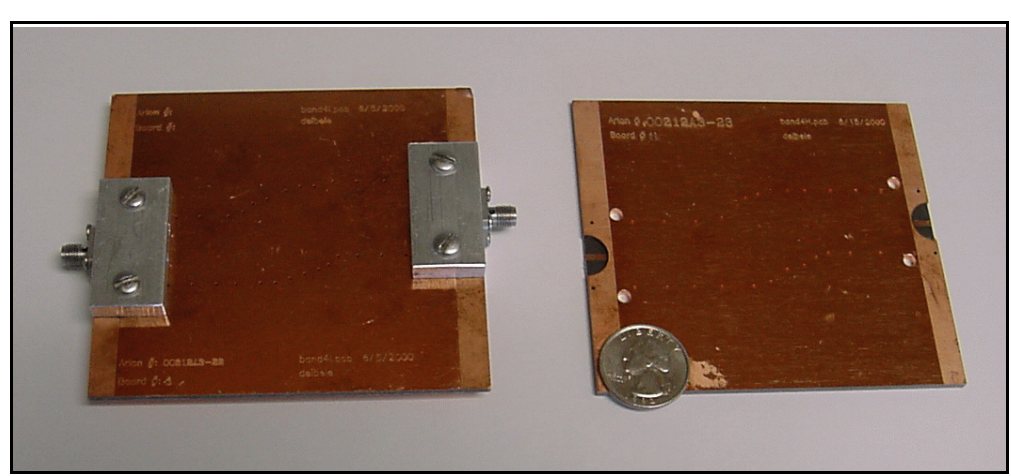

Figure 2. Picture of an assembled and an unassembled debuncher bandpass filter. The unassembled filter allows one to see that a small cutout section is designed into each board for soldering the connector onto the board. A small piece of board stock is then inserted into the cutout section to maintain the correct line impedance. The discolored sections on the ends of the boards is due to a manufacturing process to keep the cutout sections clear of copper etchant. 
electromagnetically. Excellent

results could be achieved using four coupled lines. The major variables in this design are the width of each coupled line section, the separation between traces, and the length of each coupled line. Of course, how one connects each coupled line to the next is also critical. Each filter was designed using the data contained in [3].

Each filter was designed using Arlon CuClad LX-04503355 material for the circuit board material. This particular material has a dielectric constant of

$2.33 \pm 0.02$ and has a loss tangent of 0.002. The board height is $45 \pm 0.5$ mils. This board was chosen for its tight control of dielectric constant, low loss, and strict control of board

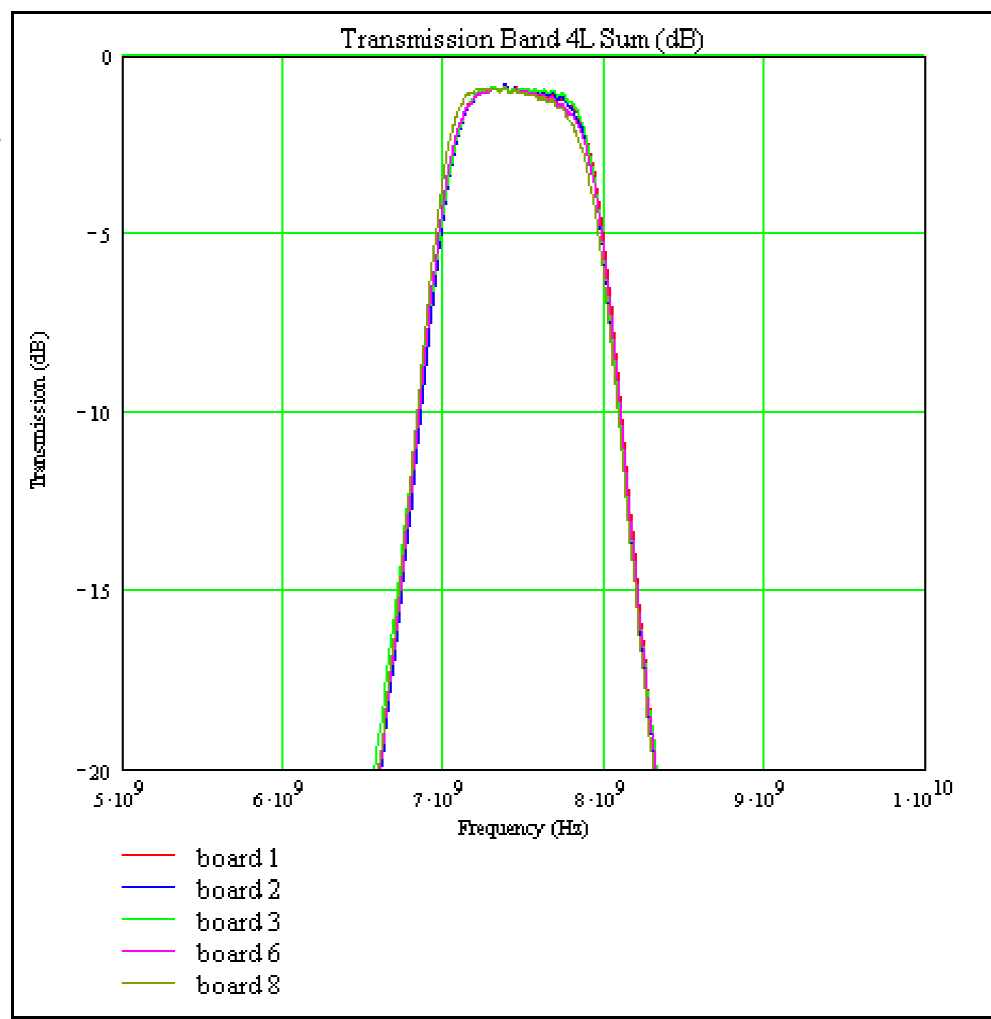

Figure 3. The transmission through 5 filters. The reliability of this technique is shown by the similarity of the responses by different boards.

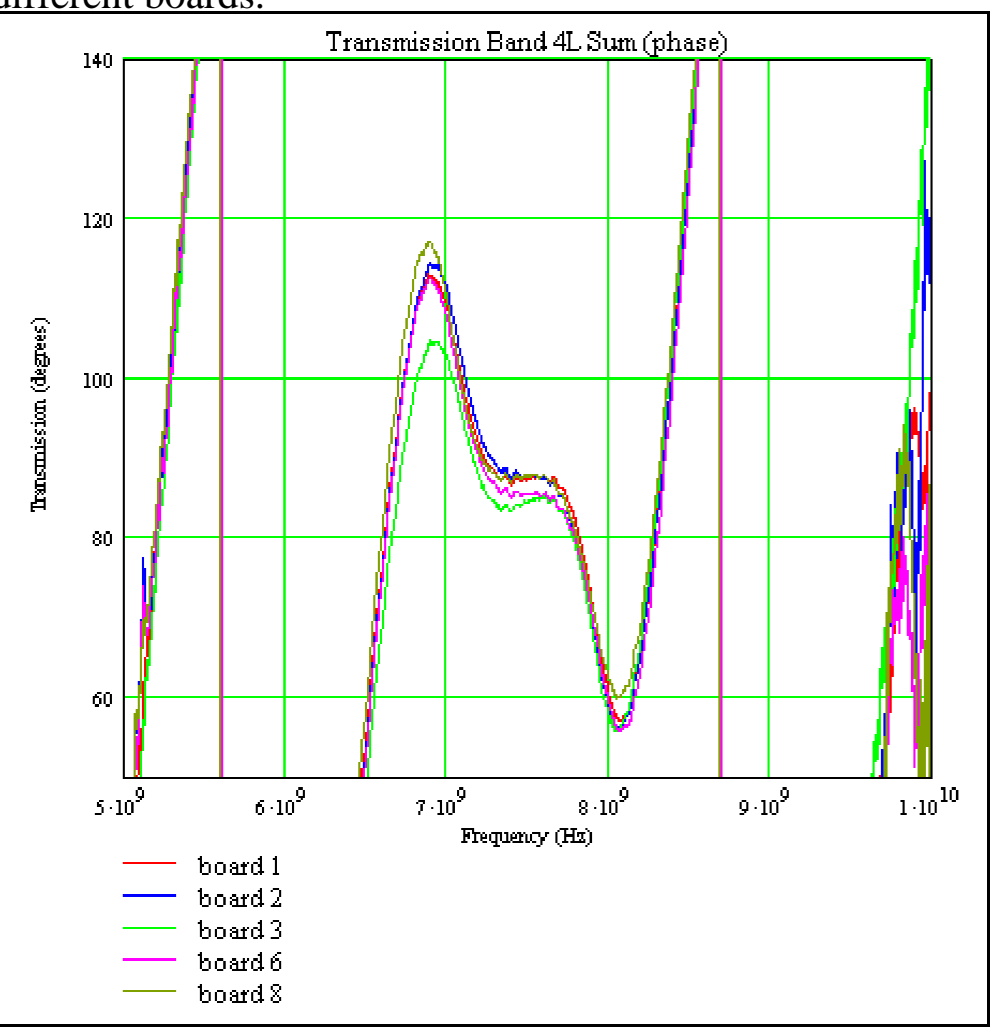

Figure 4. The phase response of the filters from Fig.3. 


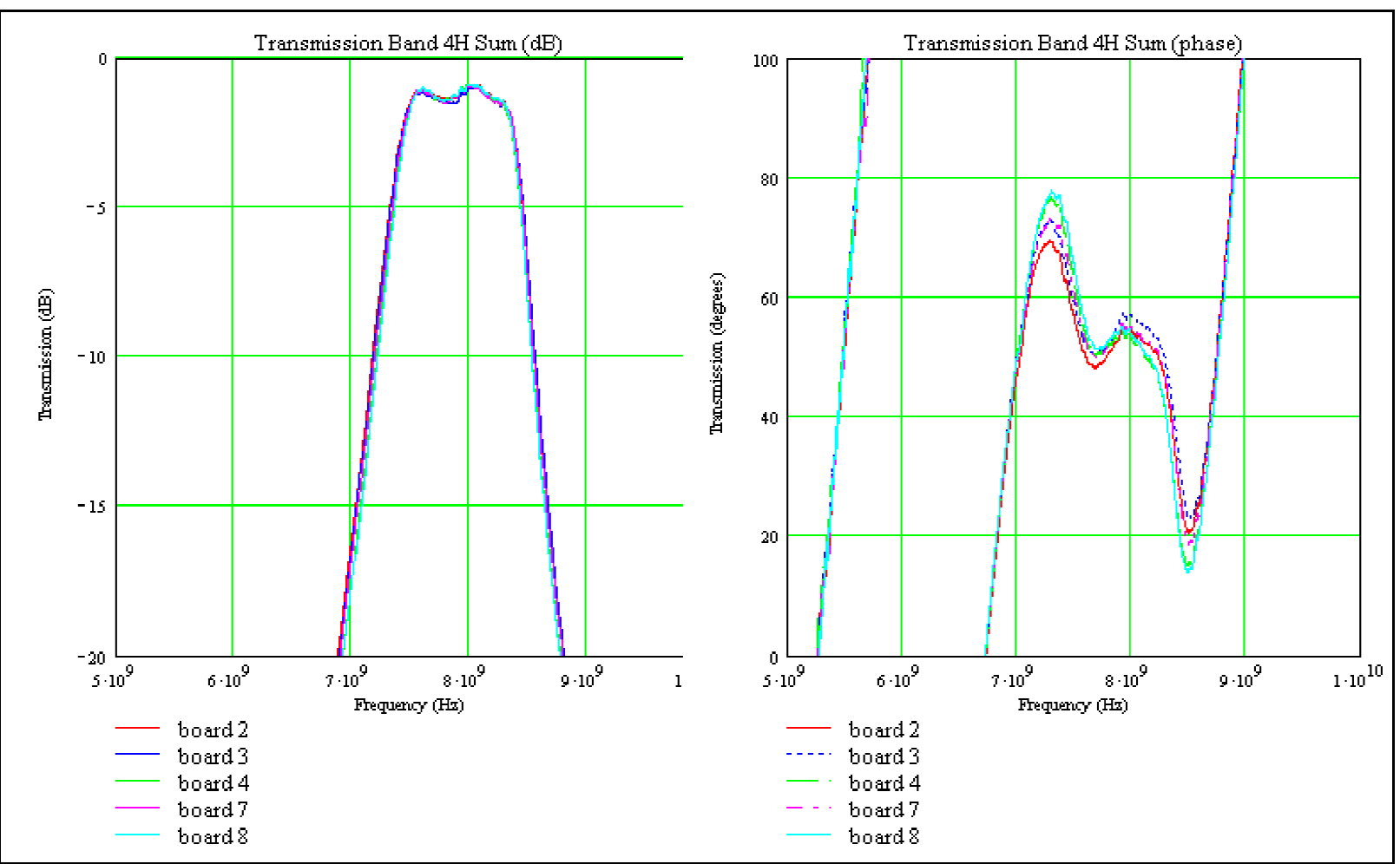

Figure 5. The measurement results of band $4 \mathrm{H}$ (momentum) in the debuncher stochastic cooling system. The magnitude and phase ripple are well within tolerances dictated by the original design criteria.

height. This particular type of board also allows one to use an easily obtainable and cheap connector, such as the MACOM 2052-1618-02. Since this technique has a high out-of-band-reflection, it is required during the installation process to use attenuators. Each filter was designed to have a $1 \mathrm{~dB}$ insertion loss in-band. Therefore, a $6 \mathrm{~dB}$ pad allows the total reflection coefficient to be no greater than $s_{11} \leq-12 d B$. A picture of a typical microwave filter is shown in Fig. 2. A picture of the measurement of a typical microwave filter is shown in Figs. 3 and 4The results of the measurement of another band are presented in Fig. 5. The repeatability and reliability of the manufacturing of the filters greatly beats the FIR technique investigated earlier. Additionally, since the boards are smaller (a typical board using this technique is 4 inches versus a typical FIR board was 30 
inches), the fabrication is significantly cheaper. If a circuit board is greater than 15 inches, it is required for the board to be pressed in a large press. Additionally, the board stock is expensive, so a short board is cheaper. Finally, the delay through the microwave resonant board is on the order of 1.4 nsec, whereas for the FIR board the delay is $3.5 \mathrm{nsec}$.

\section{Data and Measurements}

The data for the filters is reproduced in the table below.

\begin{tabular}{|l|l|l|l|l|l|l|l|l|l|l|l|l|}
\hline & $\mathrm{W}_{1}$ & $\mathrm{~S}_{1}$ & $\mathrm{~L}_{1}$ & $\mathrm{~W}_{2}$ & $\mathrm{~S}_{2}$ & $\mathrm{~L}_{2}$ & $\mathrm{~W}_{3}$ & $\mathrm{~S}_{3}$ & $\mathrm{~L}_{3}$ & $\mathrm{~W}_{4}$ & $\mathrm{~S}_{4}$ & $\mathrm{~L}_{4}$ \\
\hline $1 \mathrm{~L}$ & 43.0 & 7.0 & 435 & 95.0 & 8.2 & 438 & 66.3 & 13.0 & 440 & 43.3 & 7.0 & 448 \\
\hline $1 \mathrm{H}$ & 43.0 & 7.3 & 389 & 75.1 & 9.1 & 411 & 94.9 & 7.2 & 382 & 43.0 & 6.6 & 402 \\
\hline $2 \mathrm{~L}$ & 43.0 & 7.8 & 342 & 63.5 & 17.0 & 392 & 94.9 & 9.5 & 318 & 43.0 & 7.1 & 385 \\
\hline $2 \mathrm{H}$ & 43.0 & 8.0 & 344 & 89.9 & 12.4 & 308 & 60.6 & 20.3 & 349 & 43.1 & 8.6 & 322 \\
\hline $3 \mathrm{~L}$ & 44.9 & 9.0 & 257 & 89.9 & 22.4 & 342 & 90.0 & 20.9 & 251 & 43.0 & 14.2 & 330 \\
\hline $3 \mathrm{~L} \Delta$ & 43.0 & 9.0 & 315 & 87.0 & 16.6 & 278 & 58.6 & 24.3 & 317 & 43.1 & 9.7 & 295 \\
\hline $3 \mathrm{H}$ & 43.0 & 9.0 & 284 & 90.0 & 16.1 & 239 & 90.0 & 12.1 & 302 & 43.0 & 11.2 & 240 \\
\hline $3 \mathrm{H} \Delta$ & 43.0 & 9.0 & 283 & 95.0 & 11.6 & 262 & 62.5 & 21.5 & 290 & 43.0 & 9.8 & 277 \\
\hline $4 \mathrm{~L}$ & 43.0 & 9.1 & 273 & 79.5 & 21.6 & 197 & 79.8 & 18.8 & 288 & 43.0 & 9.1 & 202 \\
\hline $4 \mathrm{~L} \Delta$ & 42.0 & 10.0 & 259 & 93.9 & 13.3 & 238 & 78.5 & 12.5 & 268 & 42.2 & 10.1 & 243 \\
\hline $4 \mathrm{H}$ & 42.1 & 9.0 & 250 & 92.4 & 15.4 & 184 & 92.4 & 15.3 & 271 & 43.3 & 13.5 & 195 \\
\hline $4 \mathrm{H} \Delta$ & 39.0 & 9.0 & 248 & 93.6 & 10.2 & 211 & 69.5 & 11.6 & 256 & 39.3 & 9.0 & 225 \\
\hline
\end{tabular}

Table 1. The data for making each of the filters used in the Debuncher. Each filter had to be designed and optimized for its individual bandwidth and center frequency. All the units are in mils.

After the boards were etched, it was necessary to go to the circuit board manufacturer and inspect the line widths and trace quality. A common error observed in manufacture was not including 
the etch factor. Etch factor is a quantity unique to each fabrication house, and this term takes into consideration the strength of the acid bath for etching away the copper on each circuit board. It is common to add a one mil thick border to each trace as an etch factor. When the etch factor is not taken into consideration, the trace separation is off by as much as 2 mils on each coupled line, the length of each coupled lines are each off by 2 mils, and the impedance of each coupled line is incorrect. This is disastrous to the performance of the filter. If the temperature varies slightly and the boards expand or shrink, it turns out that the design is extremely stable to these changes with respect to etch factor. 


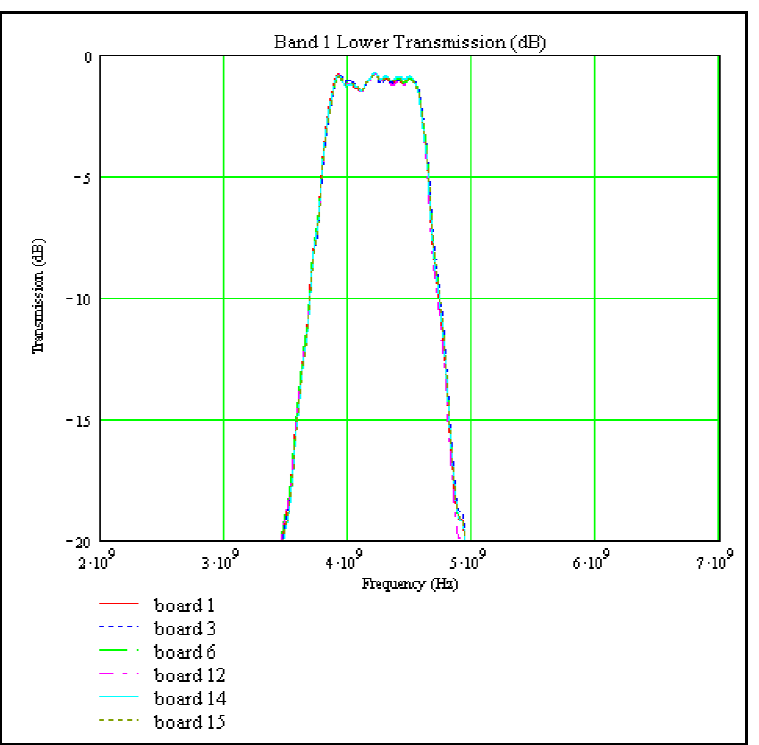

Figure 6. Band $1 \mathrm{~L}$ magnitude in $\mathrm{dB}$.

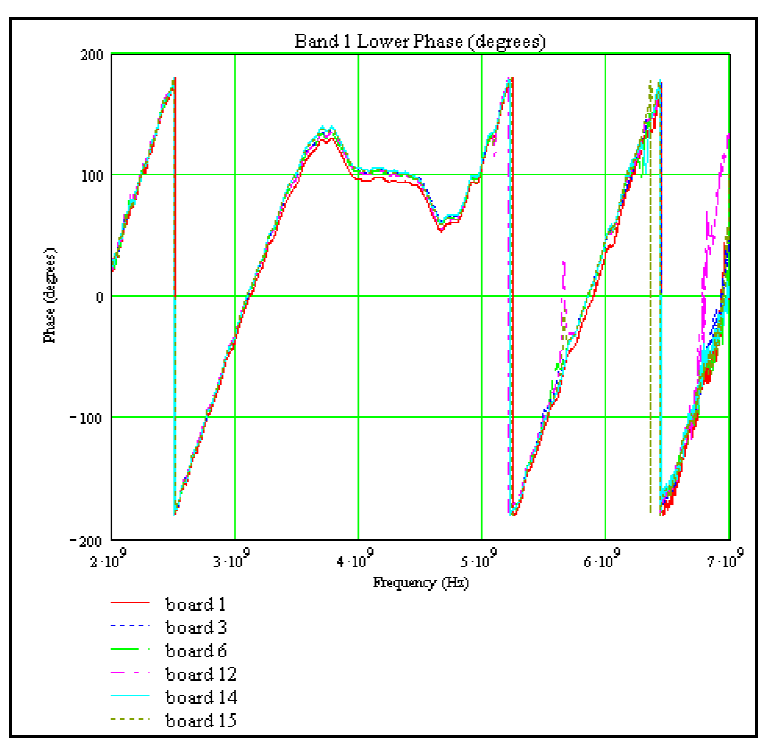

Figure 7. Band 1L phase. Delay=1.38 nsec.

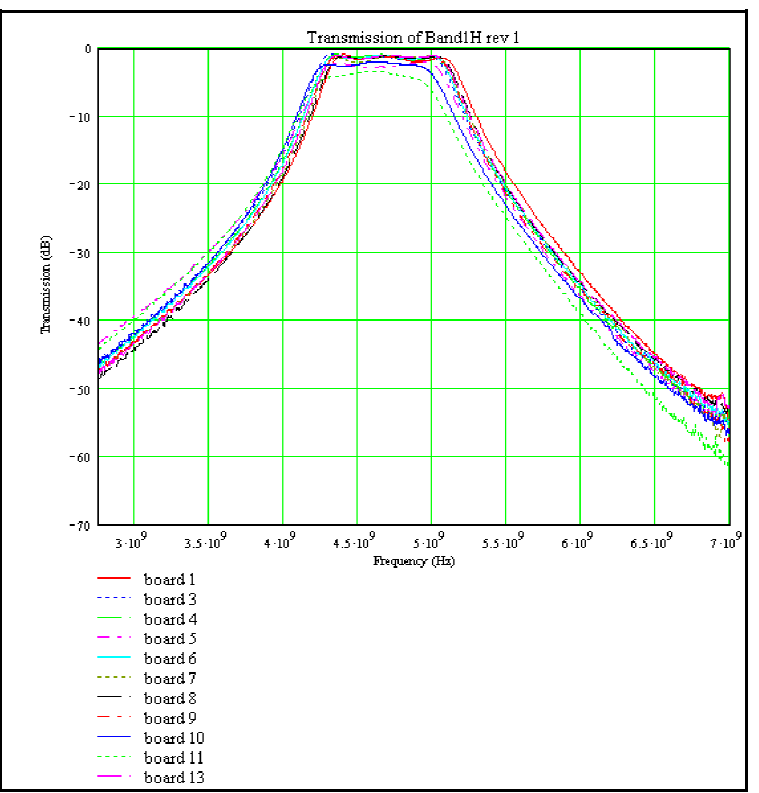

Figure 8. Band $1 \mathrm{H}$ magnitude. This picture shows the difficulty the manufacturer had in the photo-plotting and reproducibility of the manufacture of the board.

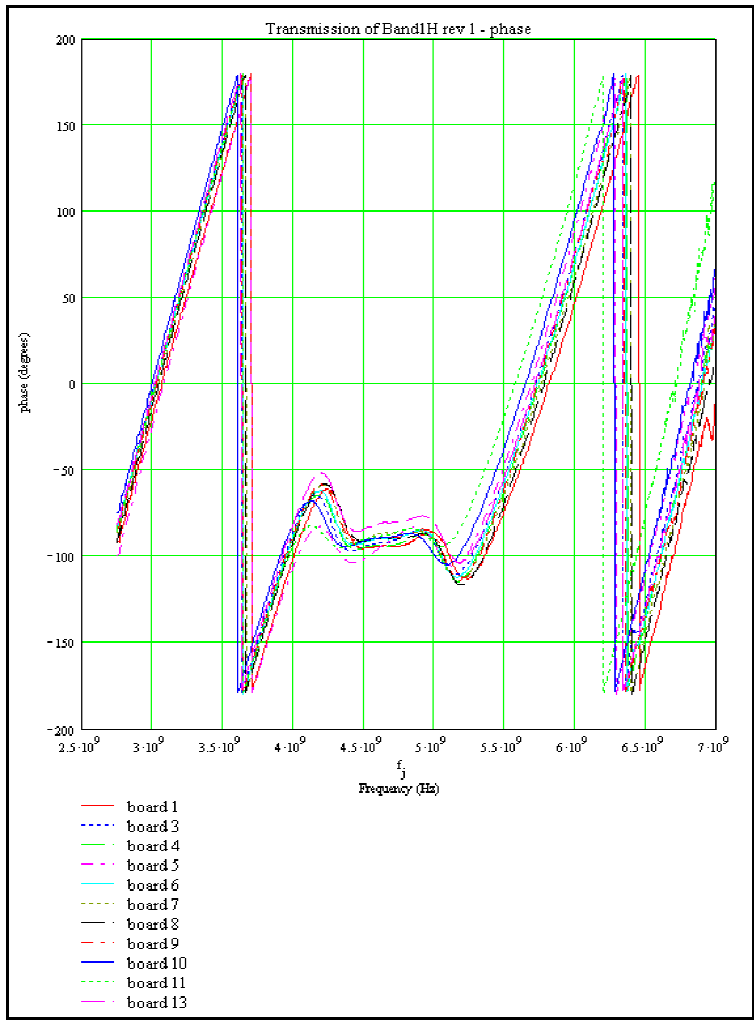

Figure 9. Band $1 \mathrm{H}$ phase. Delay $=1.40 \mathrm{nsec}$. 


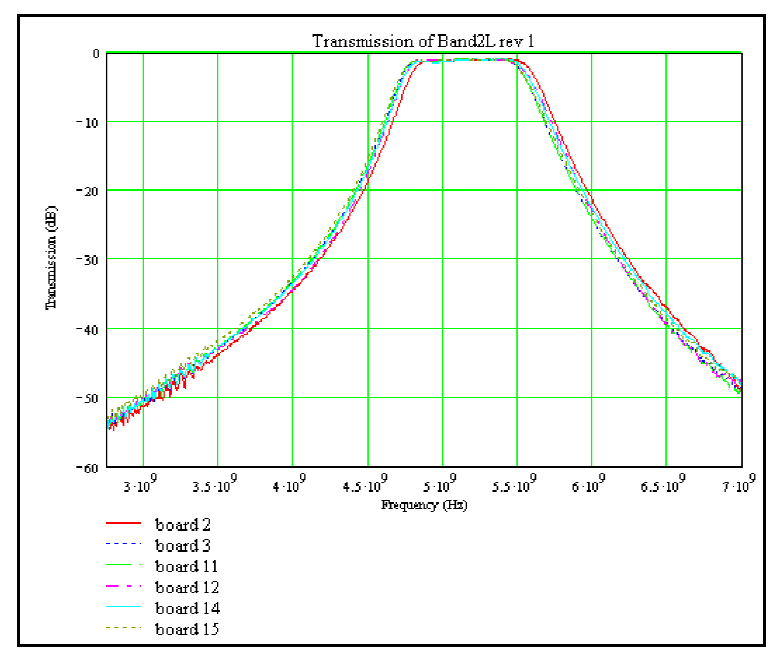

Figure 10. Band 2L magnitude.

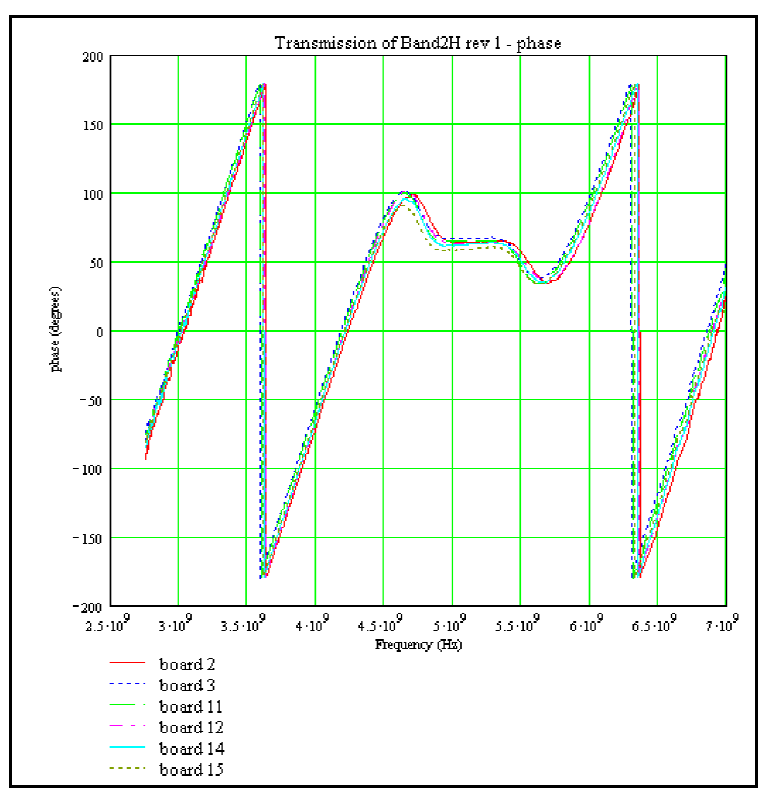

Figure 11. Band 2L phase. Delay $=1.4 \mathrm{nsec}$.

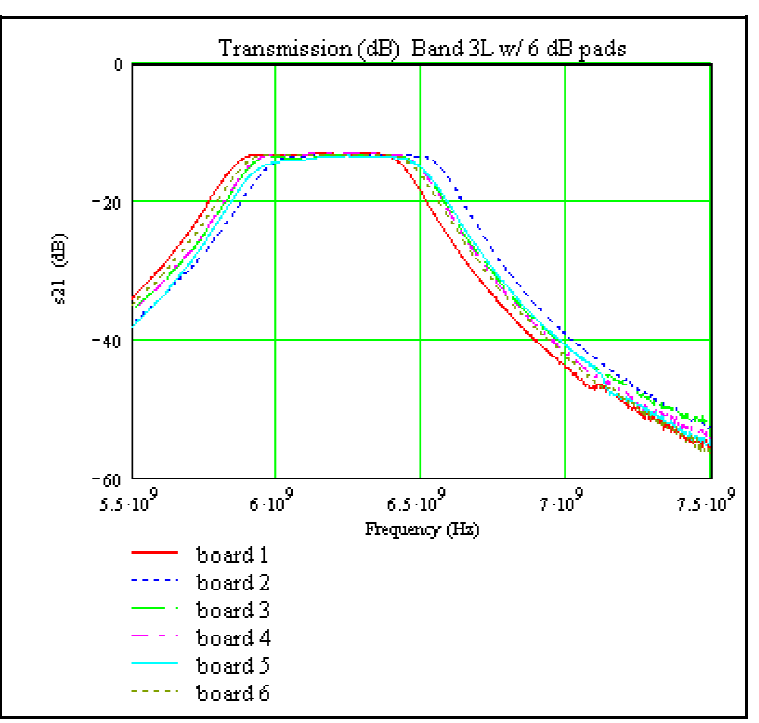

Figure 12. Band $3 \mathrm{~L}$ magnitude.

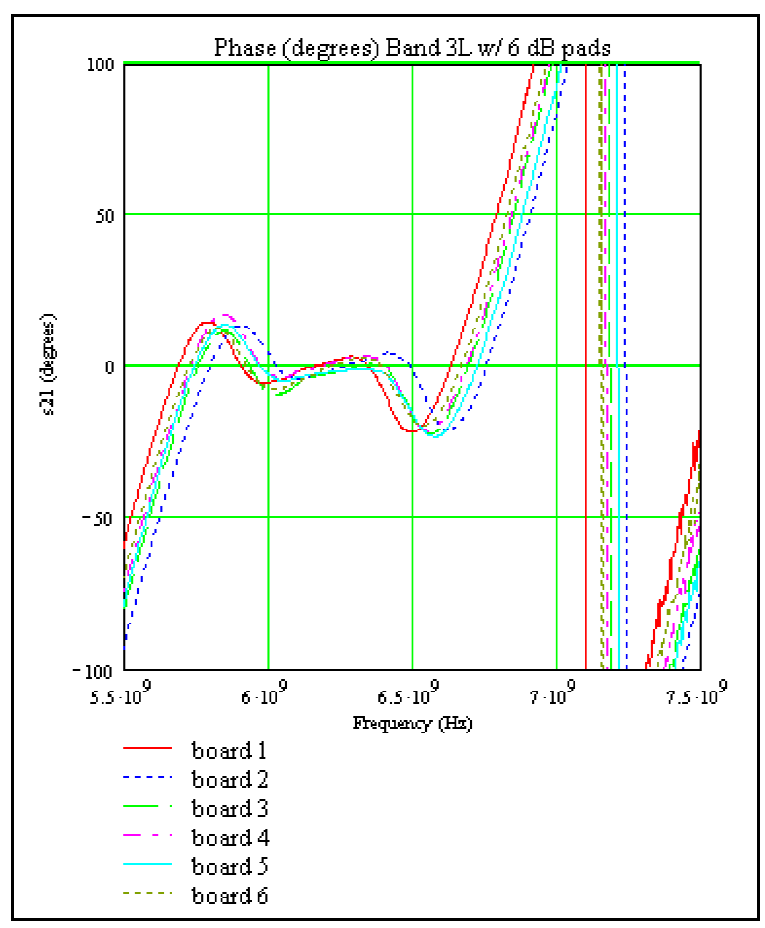

Figure 13. Band $3 \mathrm{~L}$ phase. Delay $=1.9 \mathrm{nsec}$. 


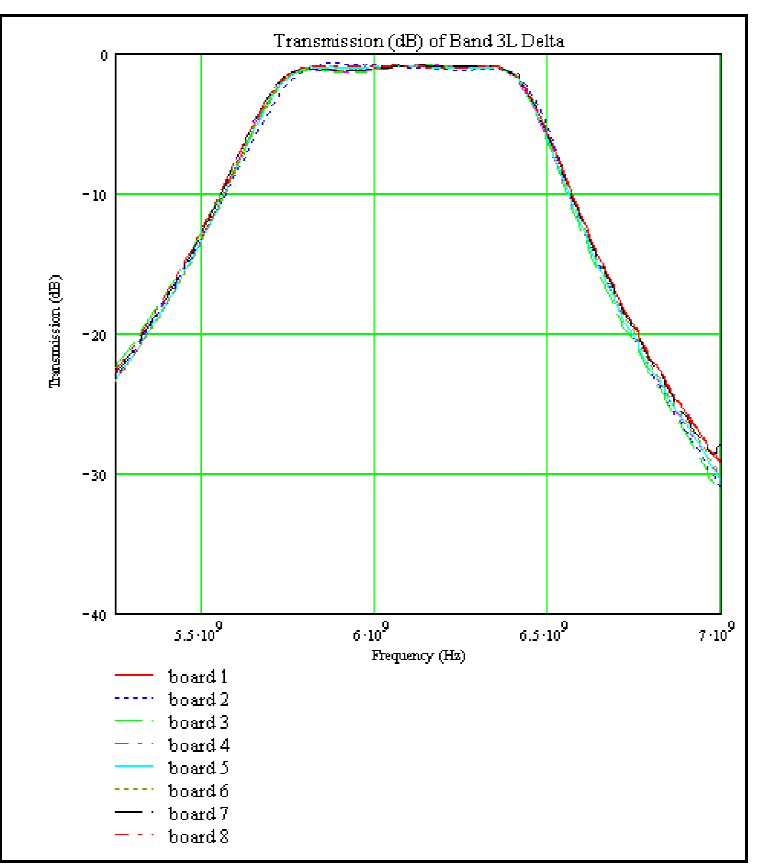

Figure 14. Band 3L $\Delta$ magnitude.

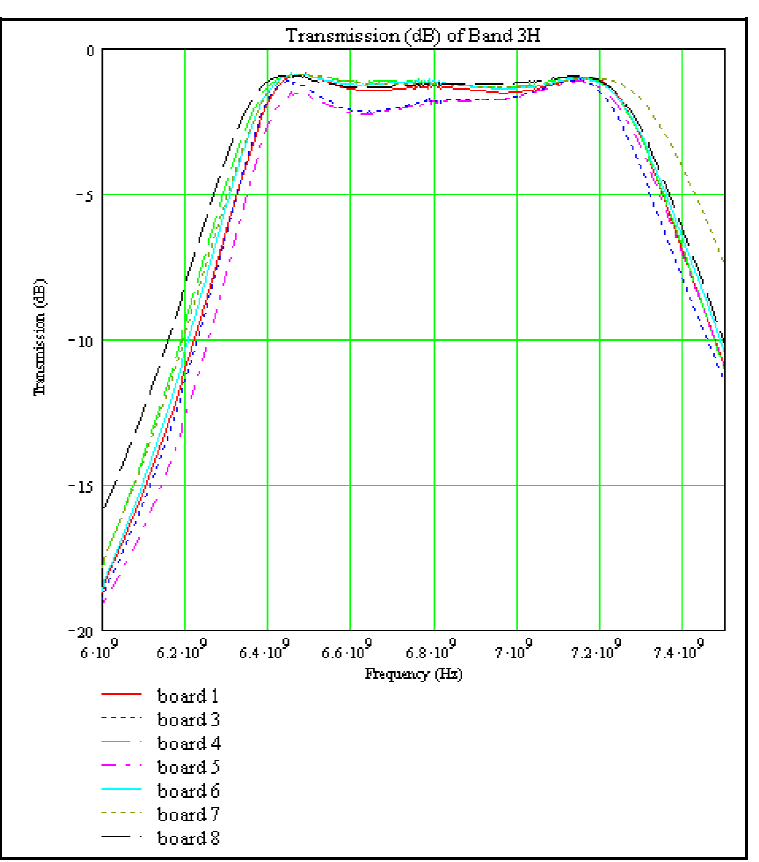

Figure 16. Band $3 \mathrm{H}$ magnitude.

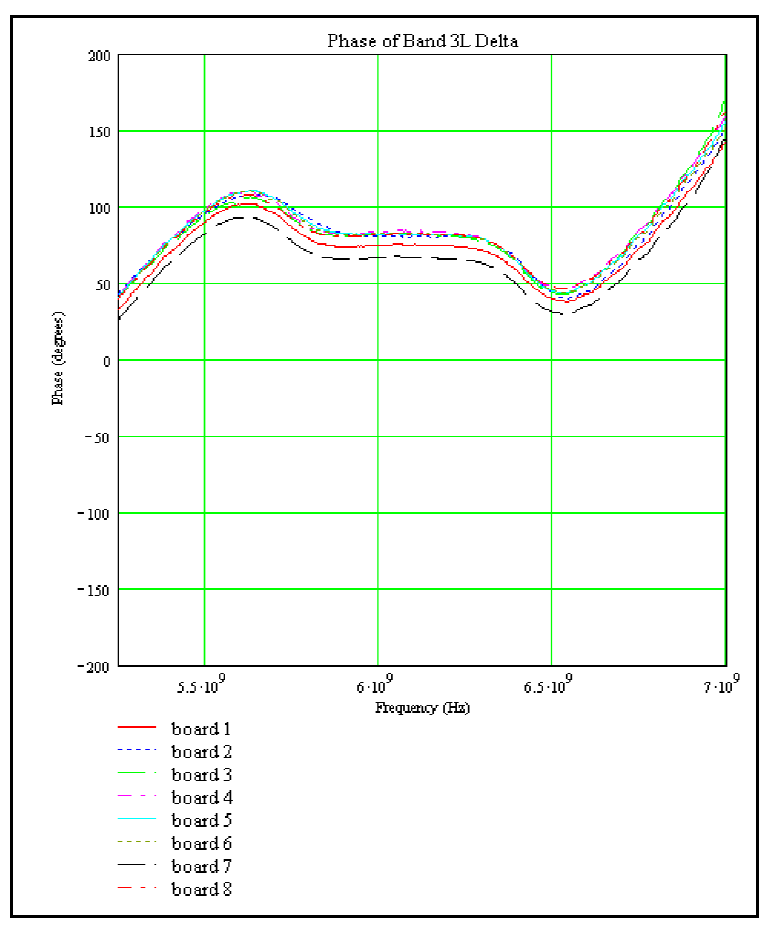

Figure 15. Band $3 \mathrm{~L} \Delta$ phase. Delay $=1.46$ nsec.

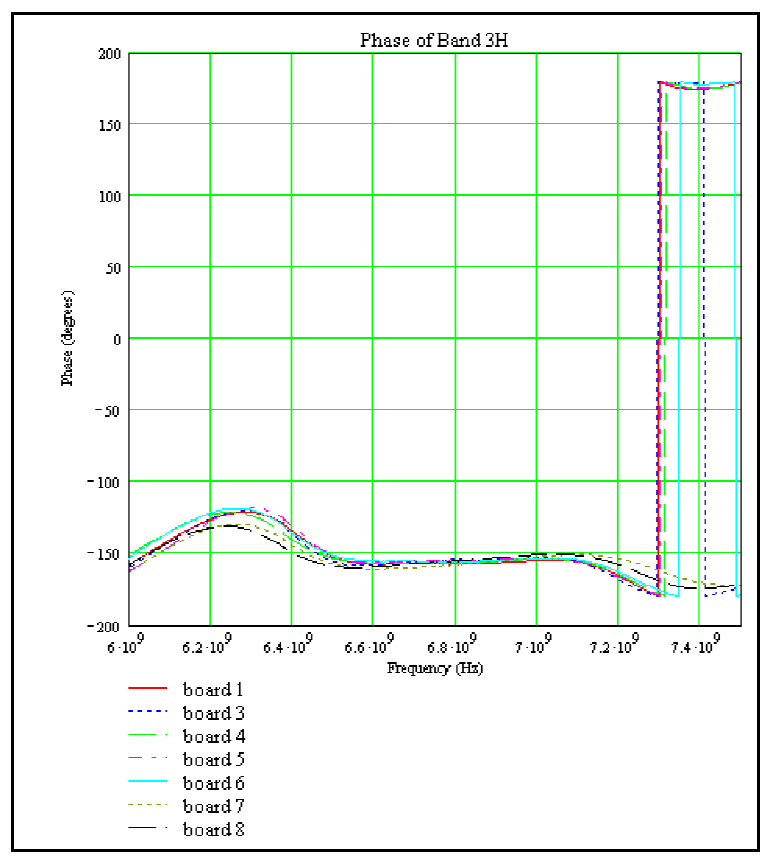

Figure 17. Band $3 \mathrm{H}$ phase. Delay $=1.26$ nsec. 


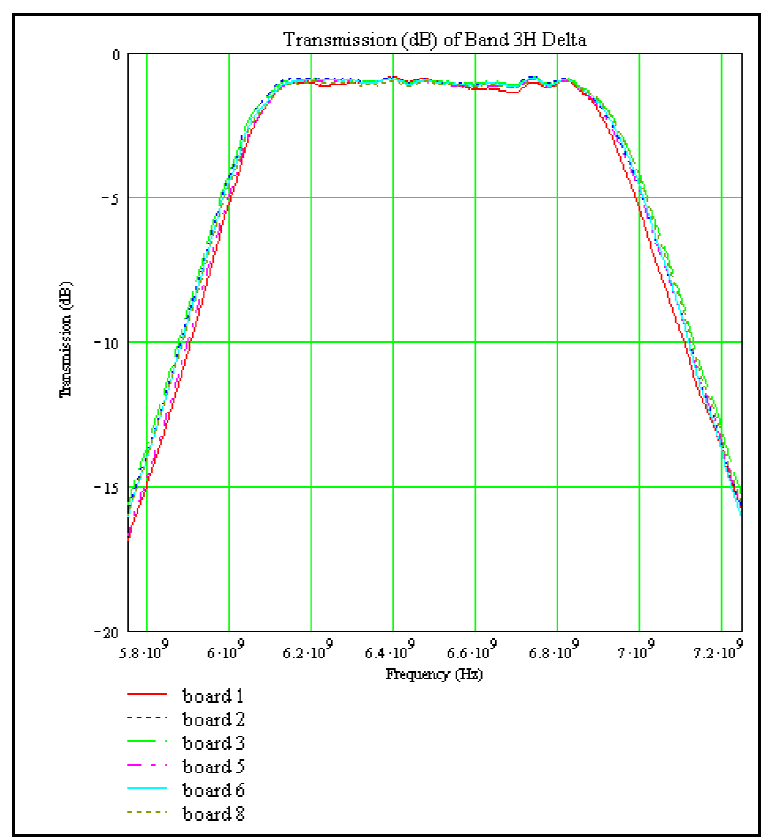

Figure 18. Band $3 \mathrm{H} \Delta$ magnitude.

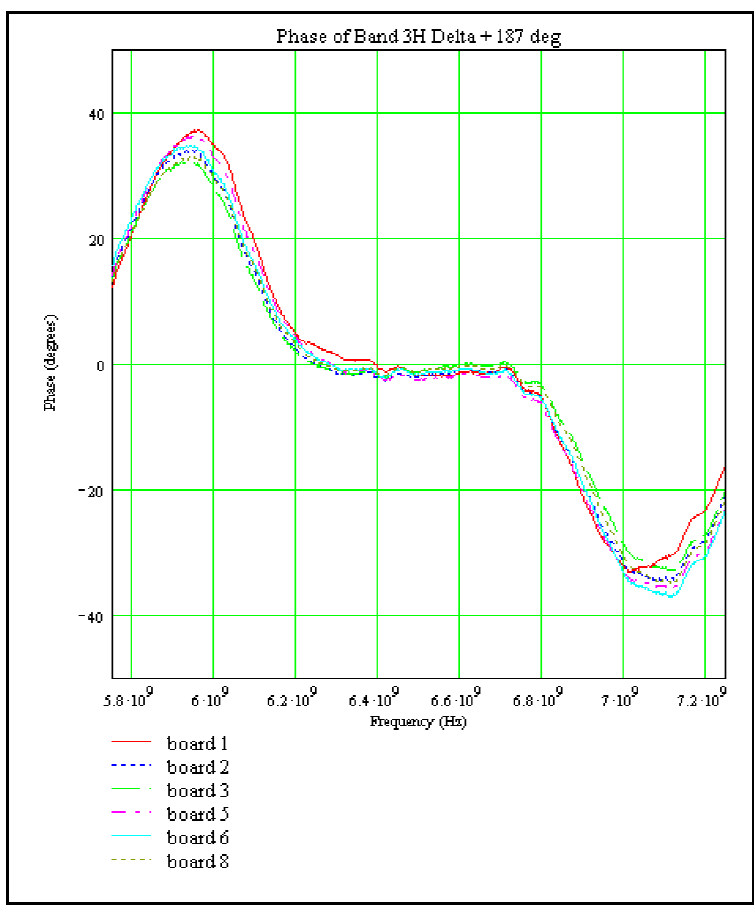

Figure 19. Band $3 \mathrm{H} \Delta$ phase, $187^{\circ}$ and delay is $1.29 \mathrm{nsec}$.

\section{Conclusion}

The technique outlined in this section shows a viable filter fabrication technique. The boards have a significant time delay savings over the FIR technique. The cost of board fabrication beats the FIR technique by a factor of 10 . The boards can be electromagnetically simulated whereas the FIR board technique cannot be electromagnetically simulated because of sheer board size. Because the board size of the filters outlined in this paper is small they are therefore relatively simple to install while the boards designed using the FIR technique are much larger and bulkier and more difficult to install.

\section{Bibliography}

[1] C. Deibele, "Synthesis of Band Pass Filters and Equalizers Using Microwave FIR Techniques," Pbar Note \#643.

[2] D. Pozar, “Microwave Engineering,” John Wiley \& Sons Publishing, $2^{\text {nd }}$ Ed., pp 474-485.

[3] D. McGinnis, “4-8 GHz Debuncher Upgrade Array Impedance Response,” Pbar note \#580. 